\title{
Encontrando todos os minimizadores de uma função através de um algoritmo de busca direta
}

\author{
Joviana S. de Souza Mateus Braga Oliveira \\ Depto de Ciências Exatas, Biológicas e da Terra, INFES, UFF \\ 28470 000, Santo Antônio de Pádua, RJ \\ E-mail: mateus.broli@gmail.com
}

\section{1-Introdução}

Neste trabalho aborda-se uma metodologia para se minimizar funções multimodais, ou seja, funções que apresentam vários minimizadores ou maximizadores. A metodologia proposta determina todos os minimizadores da função, utilizando para isto o método de busca direta Nelder Mead associado a uma técnica que consiste em transformar a função objetivo, tornando cada minimizador já encontrado um pólo repulsivo da função objetivo do problema, devido a isso denomina-se técnica de polarização.

\section{2 - O Método de Nelder Mead}

O método de Nelder-Mead, proposto por Nelder (1965), é um dos métodos de busca direta mais utilizado. A partir de um simplex inicial, o método busca melhorar o pior vértice refletindo-o em relação ao centróide dos n melhores vértices. É permitido a realização de reflexão não isométrica, expansão ou contração externa, bem como contração interna do simplex. Se nenhum desses passos produzir uma melhora, o simplex é reduzido e o processo é reiniciado. Neste método o simplex pode assumir formas arbitrárias e alguns de seus ângulos internos podem se tornar arbitrariamente pequenos.O conjunto de direções de busca pode se alterar em cada iteração, bastando executar um passo que não seja de reflexão isométrica ou de redução do simplex.

\section{3 - A técnica de polarização}

A técnica de polarização, introduzida por Henderson et al. (2010), auxilia na localização de mais de um minimizador global de uma função não negativa. A abordagem considerada parte do seguinte princípio: suponha que o primeiro minimizador global de uma função, denotado por $y^{(1)}$, já foi determinado pelo método de otimização global disponível. Em seguida, para determinar um segundo minimizador global $y^{(2)}$, emprega-se o mesmo algoritmo de otimização na resolução do subproblema:

$\left\{\begin{array}{l}\operatorname{Minimizar} f_{1}(y)=\frac{f(y)+\alpha}{\operatorname{arctg}\left\|y-y^{(1)}\right\|} \\ y \in \mathfrak{R}^{r}\end{array}\right.$

$\alpha \geq 0$

De uma maneira geral, tendo-se resolvido o subproblema (P1) e supondo-se que $n>1$ soluções já foram determinadas, procura-se a $(n+1)$-ésima solução, resolvendo o seguinte problema:

$\left\{\begin{array}{l}\operatorname{Minimizar} f_{n}(y)=\frac{f_{n-1}(y)}{\operatorname{arctg}\left\|y-y^{(n)}\right\|} \\ y \in \mathfrak{R}^{r}\end{array}\right.$

\section{4 - Resultados e Conclusões}

Nesta seção são apresentados os resultados da aplicação da metodologia proposta aplicada à três funções multimodais, onde a primeira função abordada possui seis minimizadores e as outras duas funções possuem dois minimizadores. 


\section{1 - Funções}

$$
\begin{aligned}
& f_{1}\left(x_{1}, x_{2}\right)=\left(x_{1}^{3}-3 x_{1}^{2}-x_{2}+2\right)^{2}+\left(\left(x_{1}-1\right)^{2}+x_{2}^{2}-4\right)^{2} \\
& f_{2}\left(x_{1}, x_{2}\right)=\left(x_{1}-x_{2}\right)^{2}+\left(x_{1}^{2}+x_{2}^{2}-1\right)^{2} \\
& f_{3}\left(x_{1}, x_{2}\right)=\left(x_{1}+x_{2}^{2}\right)^{2}+\left(x_{1}^{2}-x_{2}^{2}-2\right)^{2}
\end{aligned}
$$

\begin{tabular}{|c|c|c|c|c|c|c|c|c|c|c|}
\hline & \multicolumn{6}{|c|}{ Min. $f_{1}$} & \multicolumn{2}{|c|}{ Min. $f_{2}$} & \multicolumn{2}{|c|}{ Min. $f_{3}$} \\
\hline$x_{1}$ & 2.8478 & 1.7654 & 0.2346 & -0.8478 & -0.4142 & 2.4142 & 0.7071 & -0.7071 & -2.0000 & -2.0000 \\
\hline$x_{2}$ & 0.7654 & -1.8478 & 1.8478 & -0.7654 & 1.4142 & -1.4142 & 0.7071 & -0.7071 & 1.4142 & -1.4142 \\
\hline
\end{tabular}

Tabela 1: Minimizadores das funções $f_{1}\left(x_{1}, x_{2}\right), f_{2}\left(x_{1}, x_{2}\right)$ e $f_{3}\left(x_{1}, x_{2}\right)$ determinados pela metodologia proposta.

\section{2 - Gráficos}
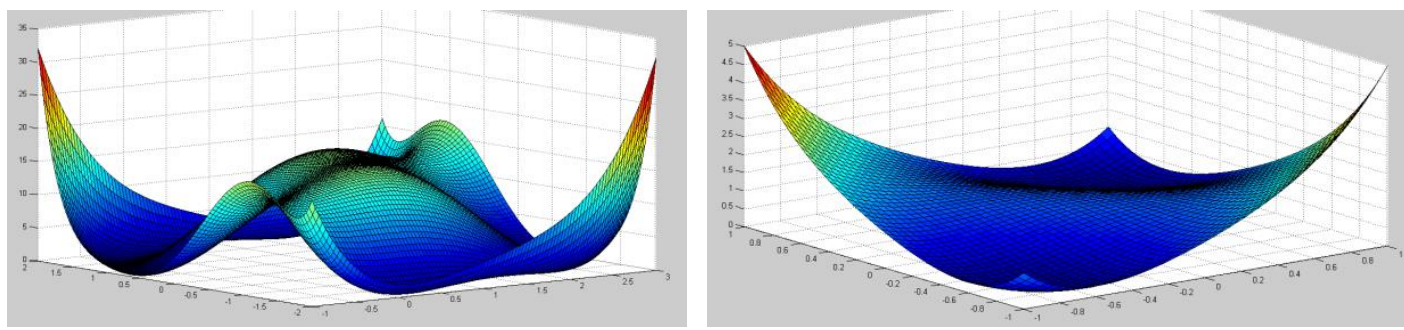

Figura 4.1: Gráfico da função $f_{1}\left(x_{1}, x_{2}\right)$ Figura 4.2: Gráfico da função $f_{2}\left(x_{1}, x_{2}\right)$

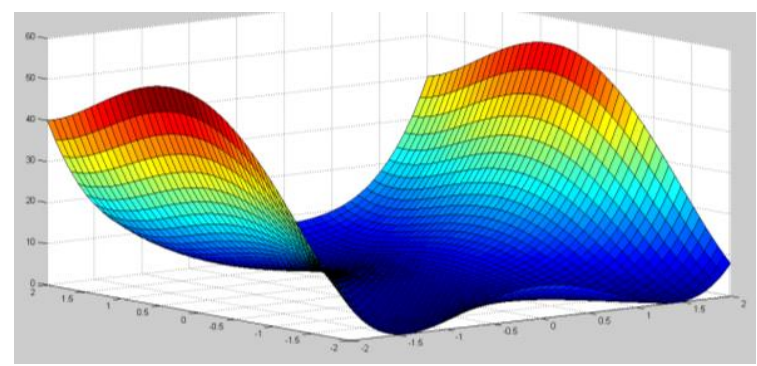

Figura 4.3: Gráfico da função $f_{3}\left(x_{1}, x_{2}\right)$

\section{5 - Conclusões}

A partir dos resultados obtidos por meio do método de Nelder Mead, com a utilização da técnica de polarização, foi possível obter todos os mínimos globais das funções mostradas anteriormente. Os resultados numéricos com a aplicação da metodologia comprovam robustez e eficiência, de maneira que todas as raízes das funçõesestudadas foram encontradas.

\section{5 - ReferênciasBibliográficas}

[1]Henderson, N., Sacco, W. F., Platt, G. M.(2010), Finding more than one root of nonlinear equations via a polarization technique: an application to double retrograde vaporization.

Chemical Engineering Research and Design, v. 88, n.5-6, p. 551-561.

[2] Nelder, J.A.; Mead, R. (1965), A simplex method for function minimization, TheComputer Journal, Vol. 7, p. 308-313.

[3] Silva, M. R., Algoritmo heurístico de busca direta para solução de problemas de programação não linear irrestrita com múltiplos ótimos. In: 42 SBPO - Simpósio Brasileiro de Pesquisa Operacional, 2010, Bento Gonçalves - RS. 